Open Access

\title{
Tumor-induced loss of mural Connexin 43 gap junction activity promotes endothelial proliferation
}

Mayur Choudhary ${ }^{1,2,5}$, Christine Naczki1, Wenhong Chen ${ }^{1}$, Keith D. Barlow ${ }^{2}$, L. Douglas Case 3,4 and Linda J. Metheny-Barlow $w^{1,2,4^{*}}$

\begin{abstract}
Background: Proper functional association between mural cells and endothelial cells (EC) causes EC of blood vessels to become quiescent. Mural cells on tumor vessels exhibit decreased attachment to EC, which allows vessels to be unstable and proliferative. The mechanisms by which tumors prevent proper association between mural cells and EC are not well understood. Since gap junctions (GJ) play an important role in cell-cell contact and communication, we investigated whether loss of GJ plays a role in tumor-induced mural cell dissociation.

Methods: Mural cell regulation of endothelial proliferation was assessed by direct co-culture assays of fluorescently labeled cells quantified by flow cytometry or plate reader. Gap junction function was assessed by parachute assay. Connexin 43 (Cx43) protein in mural cells exposed to conditioned media from cancer cells was assessed by Western and confocal microscopy; mRNA levels were assessed by quantitative real-time PCR. Expression vectors or siRNA were utilized to overexpress or knock down Cx43. Tumor growth and angiogenesis was assessed in mouse hosts deficient for $\mathrm{C} \times 43$.
\end{abstract}

Results: Using parachute dye transfer assay, we demonstrate that media conditioned by MDA-MB-231 breast cancer cells diminishes GJ communication between mural cells (vascular smooth muscle cells, vSMC) and EC. Both protein and mRNA of the GJ component Connexin 43 (CX43) are downregulated in mural cells by tumor-conditioned media; media from non-tumorigenic MCF10A cells had no effect. Loss of GJ communication by Cx43 siRNA knockdown, treatment with blocking peptide, or exposure to tumor-conditioned media diminishes the ability of mural cells to inhibit EC proliferation in co-culture assays, while overexpression of Cx43 in vSMC restores GJ and endothelial inhibition. Breast tumor cells implanted into mice heterozygous for Cx43 show no changes in tumor growth, but exhibit significantly increased tumor vascularization determined by CD31 staining, along with decreased mural cell support detected by NG2 staining.

Conclusions: Our data indicate that i) functional Cx43 is required for mural cell-induced endothelial quiescence, and ii) downregulation of Cx43 GJ by tumors frees endothelium to respond to angiogenic cues. These data define a novel and important role for maintained Cx43 function in regulation of vessel quiescence, and suggest its loss may contribute to pathological tumor angiogenesis.

Keywords: Breast cancer, Connexin 43, Gap junction communication, Pericyte, Mural cell, Endothelial cell, Angiogenesis

\footnotetext{
* Correspondence: Imetheny@wakehealth.edu

'Department of Radiation Oncology, Wake Forest School of Medicine,

Medical Center Boulevard, Winston-Salem, NC 27157, USA

${ }^{2}$ Department of Cancer Biology, Wake Forest School of Medicine, Medical

Center Boulevard, Winston-Salem, NC 27157, USA

Full list of author information is available at the end of the article
}

\section{Biomed Central}

(c) 2015 Choudhary et al. This is an Open Access article distributed under the terms of the Creative Commons Attribution License (http://creativecommons.org/licenses/by/4.0), which permits unrestricted use, distribution, and reproduction in any medium, provided the original work is properly credited. The Creative Commons Public Domain Dedication waiver (http:// creativecommons.org/publicdomain/zero/1.0/) applies to the data made available in this article, unless otherwise stated. 


\section{Background}

A functional blood vessel is composed of the endothelium, the cell layer that forms the channel through which blood flows, and mural cells, the vascular smooth muscle cells (vSMC) and pericytes that serve to support and stabilize the endothelium. Proper physical and functional association between mural cells and endothelial cells (EC) causes EC to become quiescent [1]. In addition, mural cells contribute to vessel stability via regulation of deposition of basement membrane proteins and enhancement of tight junctions between endothelial cells [2, 3]. In contrast, the vasculature formed by a tumor is highly disorganized and exhibits decreased and abnormal association with mural cells $[4,5]$, which allows the vessel to be unstable, leaky and proliferative. However, the molecular determinants that mediate the inhibitory interactions between mural cells and endothelial cells, and the mechanism(s) by which tumors prevent proper association between mural cells and the endothelium, have not been well elucidated. Knowledge of the mechanism(s) by which mural cells dissociate from vessels would significantly increase the understanding of physiological blood vessel development, as well as pathological conditions such as tumor angiogenesis in which these basic processes appear to be deregulated.

Gap junctions (GJ) are membrane channels that allow the transfer of ions, second messengers, and other small molecules between adjacent cells [6]. GJ are composed of connexin proteins, of which the product of the GJA1 gene, Connexin 43, is a main component in the vasculature. Functional heterologous gap junctions have been described between EC and mural cells [7-9]. Indeed, Cx43-based gap junctions have been shown to be required for the endothelial-induced differentiation of mural cell precursors during vessel assembly [9]. In addition, these gap junctions play a role in integrating vasopressive signals along the vessel to maintain vascular tone [10] and are required for proper coronary vessel patterning $[11,12]$. In this study, we have explored the role of $\mathrm{Cx} 43$ in the inhibitory interactions between mural cells and endothelial cells and the alteration of Cx43 expression and function in a model of tumor angiogenesis. We find that $\mathrm{Cx} 43$-based gap junction activity is required for the mural cell-induced endothelial quiescence that is characteristic of stabilized vessels, and that breast tumor cell downregulation of mural cell $\mathrm{Cx} 43$ is sufficient to release endothelial cells from this inhibition to allow endothelial proliferation. Further, we show that tumor angiogenesis is increased in a $\mathrm{Cx} 43$-deficient host. These data therefore provide a possible mechanistic explanation for the maturation defect characteristic of vasculature in tumors and other angiogenic pathologies which allows vessels to be proliferative.

\section{Methods}

\section{Cell culture and reagents}

MDA-MB-231 human breast cancer cells were obtained from the Georgetown University Repository and maintained in IMEM, 10 \% FBS. STR analysis (CellCheck, RADIL, University of Missouri) confirmed origin of these cells as MDA-MB-231. Conditioned media (CM) was prepared by incubating a $90 \%$ confluent monolayer of MDAMB-231 cells in EBM-2 (Lonza, Walkersville, MD) for $24 \mathrm{~h}$. Human MCF10A and MCF7 from the WFU Tissue Virus and Vector Core were maintained in RPMI-1640 + $10 \%$ FBS. To screen for relative potency of conditioned media, flasks of $\sim 90 \%$ confluent cells were incubated with EBM-2 for $24 \mathrm{~h}$. In some experiments, cells from the conditioning flasks were then trypsinized and counted, and all media equalized to the same cell number $/ \mathrm{ml}$ media. vSMC (primary human coronary artery smooth muscle cells, passage 5 to 8 , Lonza [5 lots] or Cascade Biosciences, Eugene, OR [1 lot]) and HBVP (human brain vascular pericytes, passage $4-8$, ScienCell, Carlsbad, CA) were maintained in SmGM-2 (Lonza). HUVEC (passage 5 to 9, Lonza), GFP-HUVEC (passage 4 to 6, Angio-Proteomie, Boston, MA), and GFP-HBMEC (human brain microvascular pericytes, passage 4-7, AngioProteomie) were maintained in complete EGM2-MV (Lonza). C3H10T1/2 (passage 12 to 14) and MDA-MB468 cells were purchased from ATCC (Manassas, VA) and maintained in low glucose DMEM (Hyclone, South Logan, UT), 10\%FBS. Eo771 mouse mammary tumor cells (kind gift of Dr. Francis Sirotnak, Memorial Sloan Kettering Cancer Center) were maintained in RPMI$1640+10 \%$ FBS. All incubations were carried out in a humidified atmosphere at $37^{\circ} \mathrm{C}$ and $5 \% \mathrm{CO}_{2}$.

\section{Measurement of endothelial proliferation in Co-culture}

Three co-culture cell models were used: (i) vSMC and HUVEC: For tumor conditioned media experiments, GFP-HUVEC (1200-1800 cells/well of 96 well plate) were co-cultured with vSMC at a ratio of 1:1.5 in EGM2-MV for $24 \mathrm{~h}$, followed by addition of Mock and MDA-MB-231 CM supplemented with $1 \%$ FBS. GFP fluorescence (Exc 485 nm, Em 520) was measured on a BMG Labtek Fluorostar Optima plate reader on day 4 as a measure of HUVEC cell number. GFP-HUVEC and vSMC monocultures plated in Mock and MDA-MB-231 CM were used as controls. For Cx43 overexpression, vSMC were nucleofected with control or pCMV6-XL5-Cx43 vector twenty-four hours prior to plating in co-culture and analyzed as above. For knockdown experiments, PKH26labeled vSMC nucleofected with non-targeting siRNA or siRNA specific for $\mathrm{Cx} 43$ were co-cultured with GFPHUVEC or in monoculture in 6-well plates. On indicated day, cells were trypsinized and counted on a hemocytometer followed by FACS analysis to determine 
relative percentage of red (vSMC) or green (HUVEC) cells in the suspension. Total cell counts from hemocytometer readings and percentage counts from FACS were used to determine number of HUVEC in the co-culture. Cocultures were also set up in the presence of $250 \mu \mathrm{M} \mathrm{Cx} 43$ GAP26 (sequence VCYDKSFPISHVR) or scrambled control peptide (GenScript, Piscataway, NJ); cultures received fresh media with GAP26 peptide on the third day of culture. (ii) $H B V P$ and GFP-HBMEC: GFP-HBMEC were co-cultured with HBVP at a ratio of $1: 1.5$ as above, except that $\mathrm{CM}$ was supplemented with $2.5 \%$ FBS. (iii) C3H1OT1/2 and HUVEC: C3H10T1/2 cells were nucleofected with non-targeting or Cx43-targeted siRNA, allowed to recover overnight, labeled with CellTracker Green, then added to PKH-26 labeled HUVEC. Controls consisted of C3H10T1/2 and HUVEC cultured alone in identical conditions. On indicated day, cells were trypsinized and quantified by FACS as above, except that red fluorescence indicated HUVEC and green indicated C3H10T1/2.

\section{Western blot analysis}

vSMC were starved 16-18 h in basal EBM-2, $0.1 \%$ BSA then stimulated with Mock or MDA-MB-231 CM for $24 \mathrm{~h}$ and lysed in RIPA buffer (1 \% NP-40, $0.5 \%$ Sodium Deoxycholate, 1 \% SDS) containing 1X Thermo Scientific Halt Phosphatase Inhibitor Cocktail and Roche Complete Mini Protease Inhibitor. Protein content was quantified and equal quantity of protein separated by SDSpolyacrylamide gel electrophoresis and transferred onto nitrocellulose membrane (Thermo Scientific, Waltham, MA). After blocking, the membrane was probed with antibodies specific for Cx37 (Abcam), Cx40 (Millipore), Cx43 (Cell Signaling, Danvers, MA), Cx45 (Sigma) and loading control (Tubulin, Labvision, Fremont, CA; $\beta$-Actin, Sigma; or GAPDH, Cell Signaling), followed by exposure to appropriate horseradish-peroxidase-linked secondary antibody (Amersham Life Sciences, Piscataway, NJ). Bound antibody was detected using chemiluminescence (ECL Plus, Amersham) and quantified using ImageJ software $(\mathrm{NIH})$ or Scion Image software. Data were normalized to loading control and expressed as relative Cx43 levels compared to corresponding mock.

\section{Nucleofection}

vSMC or C3H10T1/2 cells at $80 \%$ confluence were trypsinized and nucleofected with control non-targeting siRNA or the appropriate (human or mouse) siRNA pool directed against Cx43 (Dharmacon, Lafayette, Colorado), or pCMV6-XL5-Cx43 or control vector (Origene, Rockville, MD), using an Amaxa NucleofectorII and Primary Smooth Muscle kit solution (Lonza) per manufacturer's directions.

\section{Parachute assay}

GJ activity was measured by a noninvasive parachute assay as described [13] using vSMC as "donor" cells and HUVEC as "acceptor" cells. HUVEC acceptor cells were labeled with the nontransferable dye PKH-26 (Sigma-Aldrich, St Louis, MO) using the manufacturer's protocol, washed with PBS, resuspended in fresh media and $5 \times 10^{5}$ cells plated in 6-cm dishes. vSMC donor cells were loaded with $0.1 \mu \mathrm{M}$ calcein-AM (Sigma-Aldrich) in growth medium with $2.5 \mathrm{mM}$ probenecid (Biomol, Plymouth Meeting, PA) for $30 \mathrm{~min}$ at $37^{\circ} \mathrm{C}$. After loading, donor cells were trypsinized and $10^{5}$ cells dropped onto PKH-26-labeled acceptor cells and incubated at $37{ }^{\circ} \mathrm{C}$ for $3 \mathrm{~h}$. For Mock and MDA-MB-231 CM groups, vSMC were treated for $24 \mathrm{~h}$ prior to calcein-AM loading. For $\mathrm{Cx} 43$ alterations, vSMC were nucleofected with siRNA or plasmid twentyfour hours prior to calcein-AM loading. The GJ communication inhibitor 18- $\alpha$-Glycyrrhetinic acid (MP Biomedical, Irwine, $\mathrm{CA}$ ) was used as negative control. To assess degree of dye coupling, cells were harvested in single cell suspensions by trypsin digestion, and fluorescence detected on a FACS Calibur flow cytometer (BD Biosciences, San Jose, CA) using a $488 \mathrm{~nm}$ filter for calcein and a $585 \mathrm{~nm}$ filter for PKH-26. GJ intercellular (GJIC) communication transfer ratio was calculated using the formula: (Number of acceptor cells X Fraction of double-labeled cells)/ Number of donor cells. Data are presented as Relative Transfer Ratio, which was calculated by normalizing values to Control Mock.

\section{Confocal imaging}

GFP-HUVEC (10,000-15,000 cells/well) were co-cultured with vSMC at a ratio of 1:1.5 in EGM2-MV for $24 \mathrm{~h}$, then media replaced with EBM-2 + $1 \%$ FBS for $48 \mathrm{~h}$. Cells were then stimulated with Mock or MDA-MB-231 CM treatment for $24 \mathrm{~h}$. For immunolabeling, fixed cells were probed with mouse monoclonal anti-Cx43IF1 antibody (Fred Hutchison Cancer Research Center, Seattle, WA) followed by anti-mouse secondary antibody conjugated to Alexa Fluor 555 (Cell Signaling). Fluorescently labeled cells were imaged on a Zeiss LSM 510 Axiovert $100 \mathrm{M}$ confocal microscope (Carl Zeiss MicroImaging Inc, Thornwood, NY) using a Exc $488 \mathrm{~nm} / \mathrm{Em} 505$ (GFP-HUVEC) and Ex543/Em650 (Alexa Fluor 555) at x200 with additional digital magnification up to $\mathrm{x} 440$. The 8-bit images were obtained in a $512 \times 512$ pixel format with 6-11 optical slices of $1.7 \mu \mathrm{m}$ thickness each. vSMC-GFP-HUVEC cell pairs were marked and the crosssection of the z-stack was scanned across the X-Y plane using the orthogonal function of the LSM Image Examiner (Carl Zeiss Microimaging Inc.). Cx43 staining extending beyond margin of GFP-HUVEC was counted as heterotypic gap junction. 


\section{Quantitative RT-PCR}

Total RNA was extracted using TRIzol $^{\circ}$ and DNase digested using $\mathrm{RT}^{2}$ qPCR grade RNA Isolation kit (SA Biosciences, Frederick, MD). Synthesis of cDNA was carried out using SABiosciences $\mathrm{RT}^{2}$ First Strand Kit with 400-800 ng total sample RNA. PCR was performed using an ABI-PRISM 7000 Detection System thermal cycler (Applied Biosystems, Carlsbad, CA) in a $25 \mu \mathrm{l}$ reaction consisting of SA Biosciences $\mathrm{RT}^{2}$ qPCR Master Mix/ROS, $1 \mu \mathrm{l}$ human GJA1 or GAPDH primers (Real Time Primers, Elkins Park, PA) primers, and $1 \mu \mathrm{l}$ of template cDNA using the cycling conditions: $10 \mathrm{~min}$ at $95{ }^{\circ} \mathrm{C}$ (1 cycle): $95{ }^{\circ} \mathrm{C} 15 \mathrm{~s}, 60{ }^{\circ} \mathrm{C}$ for $1 \mathrm{~min}$ ( 45 cycles). Data were normalized to GAPDH and fold-change for $231 \mathrm{CM}$-treated relative to mock calculated using the $\Delta \Delta \mathrm{Ct}$ method [14].

\section{Mouse generation and tumor implantation}

All experiments were approved by the Wake Forest School of Medicine Institutional Animal Care and Use Committee. Mice heterozygous for the $\mathrm{Cx} 43$ gene were generated by crossing mice with the second exon of Cx43 flanked by loxP sites (Jackson Laboratories, strain \#008039, [15]) with mice in which CRE is expressed ubiquitously under control of the CMV promoter (Jackson Laboratories, strain \#006054), both of which were generated on a C57Bl/6 background. Related mice homozygous for the floxed $\mathrm{Cx} 43$ gene (which express normal levels of Cx43) were used as wild-type controls. Western analysis of mammary fat pads without tumor implantation confirmed reduction of $\mathrm{Cx} 43$ protein in the $\mathrm{Cx} 43$ Het mice to $47.3+/-10.7 \%$ that of control mice $(n=8)$. Eo771 mouse medullary adenocarcinoma cells $\left(2.5 \times 10^{5}\right)$, derived from a spontaneous mammary tumor in a $\mathrm{C} 57 \mathrm{Bl} / 6$ mouse, were injected into the inguinal mammary fat pad of WT $(n=11)$ and Cx43 Het mice $(n=$ 10). Tumor size was measured twice a week using a digital caliper, and tumor volume estimated using the formula $\left(((L+W) / 2)^{\wedge} 3\right) / 2[16]$. The experiment was terminated at 14 days post-injection.

\section{Immunofluorescence}

Eo771 mammary fat pad tumors were removed and flash frozen in OCT medium (Tissue-Tek) and cut to $7 \mu \mathrm{m} \mathrm{sec-}$ tions, allowed to thaw to room temp for $30 \mathrm{~min}$, fixed for $10 \mathrm{~min}$ in $100 \%$ acetone and blocked for $1 \mathrm{~h}$ in $3 \%$ BSA in PBS. Sections were incubated in anti-CD31 (BD Biosciences) and/or anti-NG2 (Millipore) overnight at $4{ }^{\circ} \mathrm{C}$ followed by secondary Alexa 488 or 555 (Cell Signaling) for $1 \mathrm{~h}$ at room temp and mounted with Fluorogel + DAPI (EMS). Fluorescent microscopy was performed on an Olympus IX70 scope and images acquired at 20x with a Retiga 200R camera. The area of CD31 positive fluorescent pixels across five random fields was quantified using Image J software and averaged for each of 8 tumors per experimental group. To assess vessel mural cell investiture, relative area of CD31 positive vessels were quantified for area of NG2 positive pixels on 5 random vessels per tumor, 3 tumors per group and quantified using Image J software.

\section{Statistical analysis}

Statistical analyses were performed in the Biostatistics Core Facility of the Comprehensive Cancer Center of Wake Forest University using SAS version 9.2. All data are presented as means +/- s.e.m. across experiments of the averages of the replicate values within an experiment. The significance of Cx43 knockdown/inhibition or tumor CM treatment on dye transfer or endothelial proliferation was determined using a mixed model ANOVA with linear contrasts to assess specific pairwise comparisons between groups of interest. Experimental conditions were assumed to be nested within experiments, and the Tukey-Kramer method was used to adjust for multiple contrasts. Tumor growth over time was analyzed using repeated measures ANOVA with square root transformed data to improve normality and stabilize variances. Student's t-test was used to compare gap junction quantification by microscopy, CD31 area, NG2/CD31 ratio and tumor mass; for CD31 area, data were log transformed to normalize the data. Statistical significance was set at $\mathrm{p}<0.05$.

\section{Results}

Breast tumor cells release endothelial cells from mural cell growth inhibition

The ability of mural cells to inhibit the proliferation of endothelial cells is well established $[1,17,18]$. In order to study the effects of tumors on mural cell dissociation at the initiation of angiogenesis, we first tested whether tumors reverse the inhibitory effects of mural cells in an in vitro endothelial cell-mural cell co-culture using primary human vSMC as a mural cell model and GFPlabeled HUVEC as the endothelial component. As seen in Fig. 1a, media conditioned by tumor cells had minimal effect on the proliferation of endothelial cells cultured alone compared to mock conditioned media after four days in culture $(p=0.903, \mathrm{~ns})$. Consistent with previous reports [17], endothelial cell proliferation was decreased in the presence of vSMC when co-cultured in control media (decreased 39.6+/-4.9\% from control monoculture, $\mathrm{p}<0.01$ ). In contrast, when co-cultures were first allowed to associate overnight then exposed for four days to media conditioned by MDA-MB-231 breast tumor cells, the ability of mural cells to inhibit endothelial proliferation was completely reversed. The ability of tumor conditioned media to override mural cell inhibition of endothelial proliferation was also observed using a coculture of microvascular pericytes and microvascular 


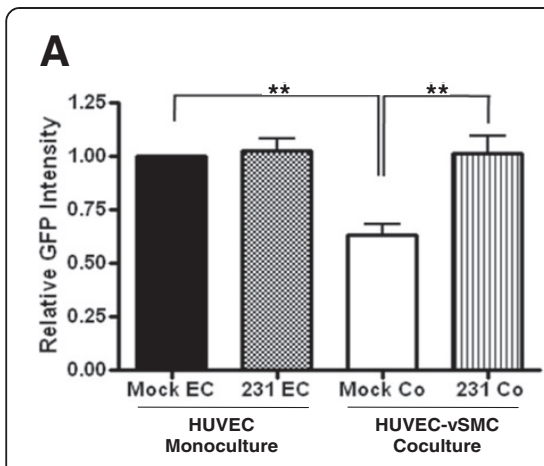

B

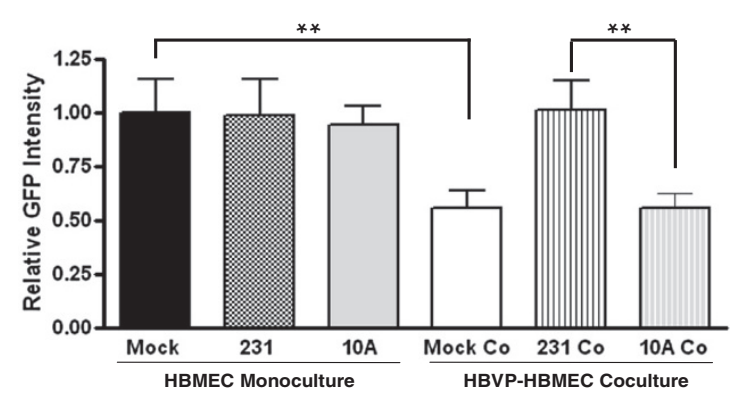

C

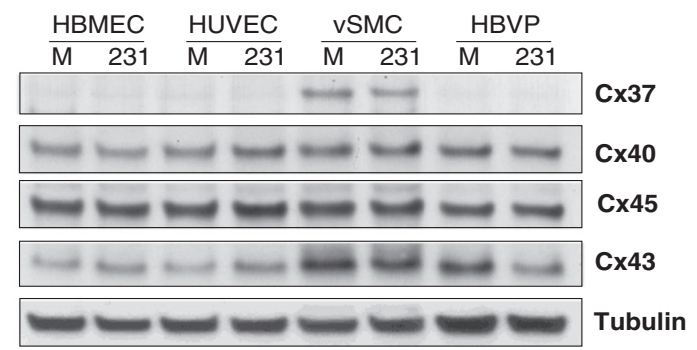

D

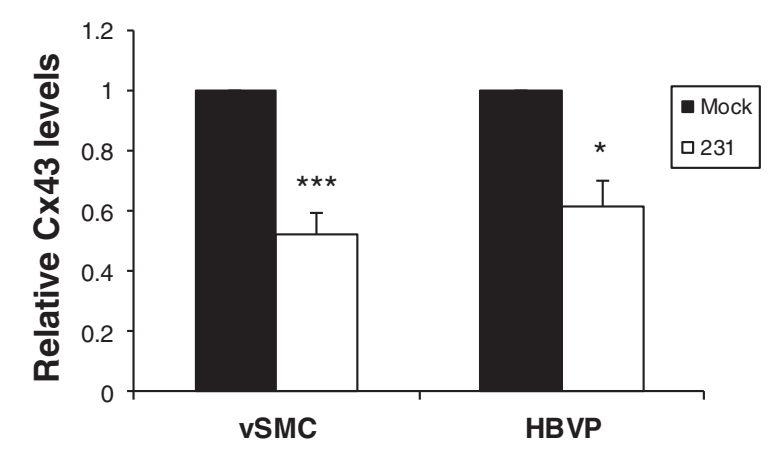

Fig. 1 Breast tumors release endothelial cells from mural cell inhibition and downregulate mural cell Cx43. vSMC and GFP-HUVEC $\mathbf{a}$ or HBVP and GFP-HBMEC $\mathbf{b}$ were plated alone or in co-culture overnight in normal growth media, then cultured in control media ('Mock') or media conditioned by MDA-MB-231 cells ('231') or MCF10A cells ('10A'). At the end of four days, fluorescence was quantified. Data shown are representative of three experiments performed in duplicate or triplicate $\left({ }^{* *} p<0.01 ;{ }^{* *} p=0.001\right)$. c Western analysis of indicated endothelial or mural cells starved overnight then stimulated for $24 \mathrm{~h}$ with control media ('Mock') or media conditioned by tumor cells ('231') and are representative of at least 2-4 replicate experiments for each cell line. $\mathbf{d}$ Quantification of Cx43 protein levels compared in vSMC and HBVP treated for $24 \mathrm{~h}$ with media conditioned by MDA-MB-231 tumor cells or control mock media normalized to tubulin levels ( $n=6$ different VSMC donor lots; ${ }^{* *} p<0.001$; for HBVP $n=3$ independent experiments with 2 different donor lots; ${ }^{*} p<0.05$ )

endothelial cells (Fig. 1b, 44.7+/-3.2\% decrease from control monoculture, $p=0.002$ ). In contrast, media conditioned by nontumorigenic MCF10A mammary epithelial cells did not promote endothelial proliferation in co-culture. The tumor-induced loss of the ability of mural cells to inhibit endothelial proliferation was unlikely due to a decrease in mural cell number following exposure to tumor conditioned media, as tumor conditioned media stimulates proliferation of mural cells (Additional file 1: Figure S1). This co-culture system demonstrates tumor-dependent subversion of stabilizing mural cell-endothelial cell interactions and provides a means to interrogate the mechanisms by which tumors disrupt inhibitory signals required for this effect.

\section{Breast tumor cells downregulate $\mathrm{Cx} 43$ protein in mural cells but not endothelial cells}

Since mural cell mediated inhibition of endothelial proliferation is reportedly contact-dependent [17], we analyzed expression of gap junctional molecules in endothelial cells and mural cells following exposure to media conditioned by breast cancer cells. While no consistent decreases in connexin expression in response to MDA-MB-231 tumor cell conditioned media was observed in either endothelial cell line, tumor conditioned media decreased total protein levels of $\mathrm{Cx} 43$ in both mural cell types after $24 \mathrm{~h}$ treatment (Fig. 1c). Although a tumor-induced decrease in Cx37 in vSMC was also detected, previous reports indicate that heterocellular junctions between vascular endothelial cells and mural cells are composed primarily of mural cell Cx43 [9] and endothelial Cx43/40 [19], with limited presence of $\mathrm{Cx} 37$ at heterocellular junctions in the microvasculature $[19,20]$. We therefore elected to further pursue the role of $\mathrm{Cx} 43$ regulation in mural cells. The ability of MDA-MB-231 cell conditioned media to decrease $\mathrm{Cx} 43$ protein levels was consistently observed in human vSMC isolated from at least 6 out of 7 different donors and HBVP from at least two different donors, with 
Cx43 protein levels reduced $48+/-7.1 \%$ and $39+/-9.0 \%$ (Fig. 1d) in responding cells, respectively.

\section{Breast tumor conditioned media inhibits Cx43-based GJ Communication between EC and MC}

We next addressed whether breast tumor cell-induced loss of vSMC Cx43 affected heterotypic GJ communication between vSMC and endothelial cells using a parachute dye transfer assay quantified by flow cytometry. In agreement with previous studies [21], significant dye transfer was observed between mural cells and endothelial cells (Fig. 2a, b). In contrast, vSMC exposed to breast tumor conditioned media demonstrated a significant decrease (to $22.3+/-5.0 \%$ of control) in capacity to transfer dye to endothelial cells (Fig. 2b), suggesting that tumor media prevents the formation of functional heterocellular gap junctions. Similarly, knock down of $\mathrm{Cx} 43$ by siRNA also nearly completely abolished the transfer of dye from vSMC to endothelial cells (down to $21.2+/-5.1 \%$ of control) indicating that $\mathrm{Cx} 43$ is the main mural cell connexin protein mediating GJ communication with endothelial cells. Lysates from vSMC monocultures plated in parallel probed for total $\mathrm{Cx} 43$ confirm the magnitude of protein loss in response to the indicated treatment (Fig. 2c). The chemical GJ inhibitor 18- $\alpha$-glycyrretinic acid, which does not affect $\mathrm{Cx} 43$ levels, nearly completely abolishes the transfer (Fig. 2b, c), demonstrating that observed dye transfer is mediated by GJ. Consistent with this, confocal detection of Cx43 gap junctions extending between mural cells and endothelial cells in co-culture, which seemed to preferentially form when mural cells oriented themselves over endothelial cells, was quantifiably decreased following treatment with tumor conditioned media $(3.19+/-0.32$ mock vs. $1.43+/-0.47$ with 231 conditioned media, $p=0.01$, Fig. $2 \mathrm{~d}$ ). Together these data indicate that tumor cells dowregulate the major mural cell connexin mediating GJ transfer between mural cells and endothelial cells to disrupt established heterotypic GJ communication.

\section{Regulation of $\mathrm{Cx} 43$ by tumor cells}

In order to determine whether cells other than MDA-MB231 possess the ability to downregulate $\mathrm{Cx} 43$ in mural cells, we screened conditioned media from a panel of human breast cancer cell lines. Consistent with its inability to release endothelial cells from mural cell inhibition, media from immortalized non-tumorigenic mammary epithelial cell line MCF10A did not alter Cx43 levels in vSMC after $24 \mathrm{~h}$ treatment (Fig. 3a). Similarly, media from less aggressive estrogen receptor positive $(\mathrm{ER}+)$ cells such as MCF7 also did not consistently diminish Cx43 levels, whereas media from more highly aggressive ER-cells such as the MDA-MB-468 cells decreased Cx43 protein levels more similar to that seen with MDA-MB-231 CM (45\% and $56 \%$ respectively) (Fig. $3 \mathrm{~b}$ ).

Mechanistically, we determined that the downregulation of Cx43 protein by MDA-MB-231 tumor cells is time- and dose-dependent (Fig. 3c, d). Although small changes in $\mathrm{Cx} 43$ protein levels may be evident at shorter time points ( $2 \mathrm{~h}$, relative $\mathrm{Cx} 43$ protein 0.88 compared to $2 \mathrm{~h}$ mock, $n=3, p=0.16$, ns; $4-5 \mathrm{~h}$, relative Cx43 protein $0.78, n=4 . p=0.09, \mathrm{~ns})$, significant decreases in $\mathrm{Cx} 43$ protein are not observed until after more prolonged exposure to $231 \mathrm{CM}$. Quantitative PCR analysis demonstrates that exposure to $231 \mathrm{CM}$ results in Cx43 mRNA decrease that is evident within $4 \mathrm{~h}$ (down to $56.9+/-5.5 \%$ control) and continues to decrease through $12 \mathrm{~h}$ (down to $28.4+/-4.0 \%)$ compared to mock media, suggesting that the loss of $\mathrm{Cx} 43$ protein is mediated in part by decrease in mRNA (Fig. 3e).

\section{Functional Cx43-containing $\mathrm{GJ}$ are required for mural cell-induced endothelial growth inhibition}

We next addressed the functional significance of Cx43 loss in mediating mural cell-endothelial cell growth inhibitory interactions. $\mathrm{Cx} 43$ has been shown to be required for endothelial cell contact-induced differentiation of mesenchymal mural precursor cells [9]. Consistent with previous reports [17], the proliferation of endothelial cells in coculture with C3H10T1/2 mural precursor cells was significantly reduced compared to endothelial cells plated alone (down to $56.5+/-8.3 \%, \mathrm{p}<0.05$, Fig. 4a); knockdown of Cx43 in C3H10T1/2 cells by siRNA significantly reverses this inhibition of endothelial proliferation (Fig. 4b). We next addressed whether Cx43 expression is similarly required for the endothelial growth inhibition exerted by fully differentiated vSMC cells. While differentiated vSMC exhibit significant growth inhibition on endothelial cells (63.0+/-14.4\%, p < 0.005, Fig. 4c), siRNA knockdown of Cx43 similarly attenuates the ability of vSMC to inhibit endothelial proliferation, indicating a requirement for mural cell Cx43 in this function. Western blot analysis shows Cx43 levels were significantly reduced following siRNA treatment while other connexins remain virtually unaltered (Fig. 4b, d). These data suggest that the observed requirement for $\mathrm{Cx} 43$ in mural cell-mediated endothelial inhibition is a general phenomenon.

Since Cx43 can reportedly confer anti-proliferative effects that are independent of its ability to form GJ [22], we sought to determine whether the observed reversal of mural cell-mediated endothelial growth inhibition was dependent on GJ activity. To distinguish this, the coculture assay was performed in the presence of the blocking peptide Cx43 GAP26 which blocks the formation of Cx43 gap junction channels between cells (reviewed in [23]) but does not affect $\mathrm{Cx} 43$ protein levels. In the presence of a scrambled control peptide, vSMC cells retain the 

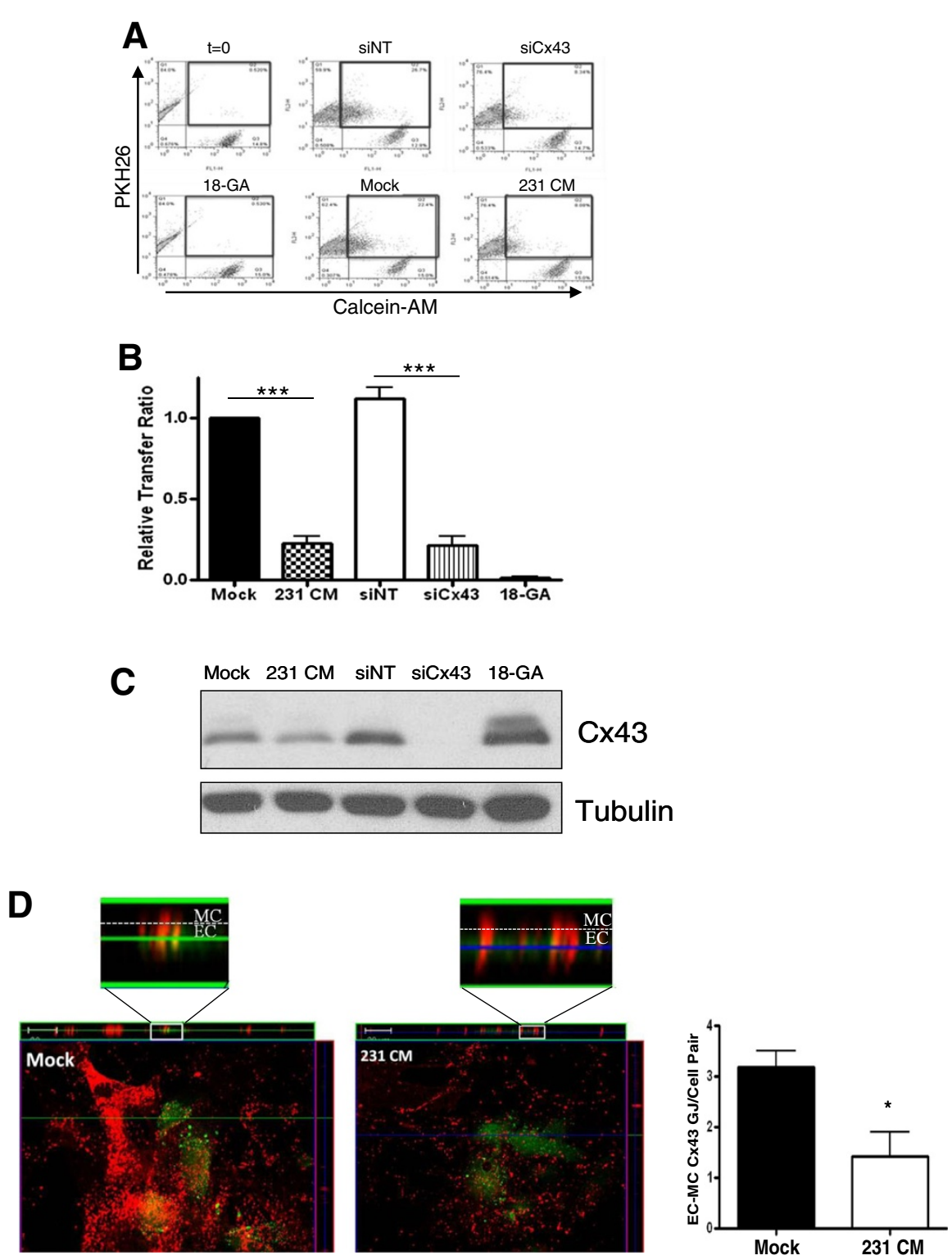

Fig. 2 Gap junction communication between mural cells and endothelial cells requires mural cell Cx43 and is decreased by tumor cells. Untransfected vSMC or vSMC nucleofected with non-targeting ('siNT') or Connexin43-specific ('siCx43') siRNA were treated with control ('Mock') or media conditioned by MDA-MB-231 cells ('231 CM'), loaded with calcein-AM, and plated onto PKH26-labeled HUVEC. Dye transfer from vSMC to HUVEC was quantified using flow cytometry. a. Representative flow cytometry dot plots showing dye transfer as percentage of double-labeled cells in upper right quadrant. b. Ratio of dye transfer as calculated in Materials and Methods. Data represent the mean of four to five independent experiments performed in triplicate $+/$-s.e.m. (duplicate for $18-G A$ ); ${ }^{* *} p<0.001$. c. Western analysis of Connexin 43 in vSMC samples incubated in parallel with experiment from A. d. vSMC and GFP-HUVEC were plated in co-culture for $72 \mathrm{~h}$ as in 'Methods', then stimulated for $24 \mathrm{~h}$ with control media ('Mock') or media conditioned by MDA-MB-231 cells ('231 CM'), and the number of heterocellular Cx43-expressing junctions (red) extending between endothelial cells (green) and mural cells quantified by confocal Z-stack analysis. Top panel, representative confocal images; inset, magnification of z-stack image of $\mathrm{C} \times 43$ gap junction. Bottom panel, quantification of $\mathrm{C} \times 43$-positive heterotypic gap junctions as seen in top panel. Data represent the quantification from paired cells over three experiments $\left(n=46-48\right.$ cell pairs each condition) $+/-$ s.e.m. $\left({ }^{*} p<0.05\right)$

ability to inhibit endothelial proliferation (decrease of $30+/-4.5 \%$ compared to EC mono, $\mathrm{p}<0.05)$; in contrast, the Cx43 GAP26 blocking peptide nearly completely reversed the ability of vSMC to inhibit endothelial growth (EC mono 17.7+/-0.3, GAP26 Co 16.3+/- 1.2, ns; Fig. 4e).
The Cx43 GAP26 peptide had no significant effect on proliferation of endothelial cells alone (Additional file 2: Figure S2). Together these data indicate that mural cellmediated endothelial growth inhibition requires gap junction activity that is dependent on mural cell $\mathrm{C} x 43$. 
A
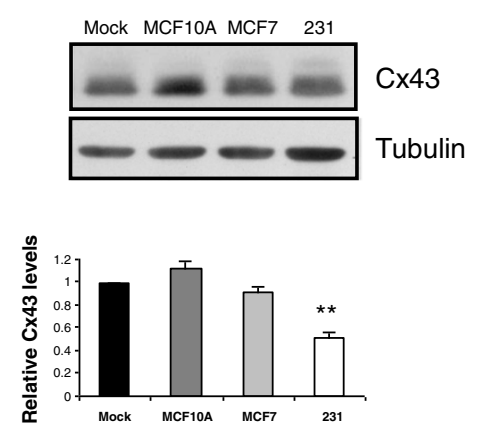

B
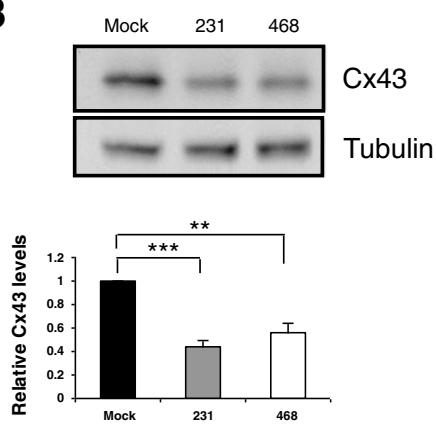

C

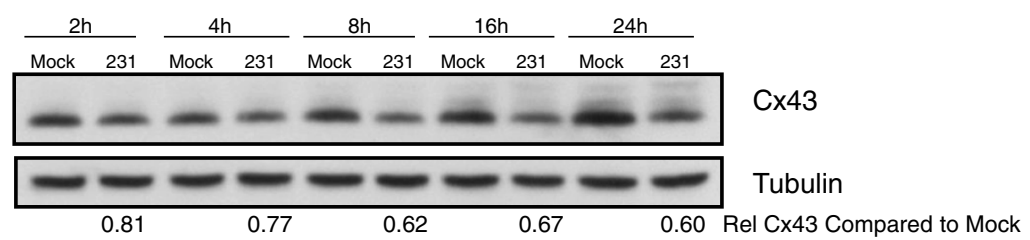

D

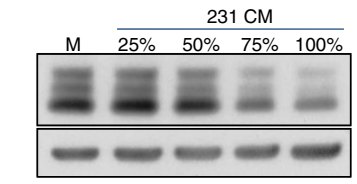

$\mathrm{Cx} 43$

Tubulin

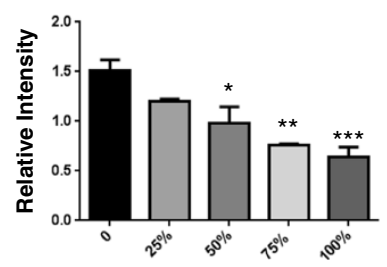

E

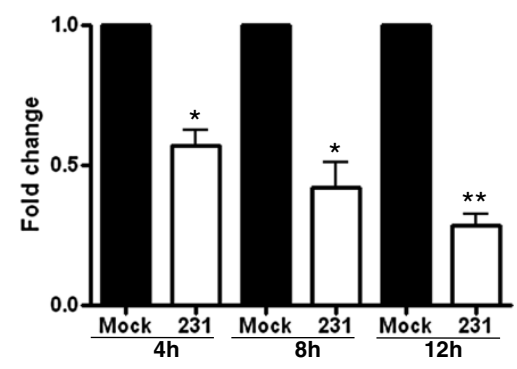

Fig. 3 Breast tumor downregulation of CX43 in VSMC is time- and dose- dependent. a, b. vSMC were stimulated for $24 \mathrm{~h}$ with media conditioned by the indicated cell line and lysates analyzed for Cx43 levels. Bottom panels represent quantification of $\mathbf{a} n=4$ experiments, $\mathbf{b} n=5$ experiments, ${ }^{*} p<0.05 ;{ }^{* *} p<0.01 ;{ }^{* * *} p<0.001$. c. vSMC were treated for the indicated time with media conditioned by MDA-MB-231 cells and lysates analyzed by Western. Data representative of two to four experiments. $\mathbf{d}$ VSMC were treated for $24 \mathrm{~h}$ with media conditioned by varying dilutions of MDA-MB-231 cell CM. Bottom panel represents quantification from 3 independent experiments. e. mRNA was isolated and subjected to quantitative PCR analysis. Data were normalized to GAPDH levels and fold change compared to Mock; data represent the mean of three independent experiments each performed in technical triplicate $\left({ }^{*} p<0.05 ;{ }^{* *} p<0.01\right)$

Breast tumor cell release of endothelial cells from mural cell inhibition is dependent on downregulation of Cx43 In order to determine whether loss of Cx43 alone is responsible for the release of endothelial inhibition, we tested whether overexpression of Cx43 was sufficient to restore mural cell growth inhibition of endothelial cells. Although ectopic Cx43 expression does not increase basal GJ dye transfer between mural cells and endothelial cells, mural cells nucleofected with a wild-type Cx43 expression plasmid retain functional gap junctions with endothelial cells despite the presence of tumor media (Fig. 5a; Cx43 Mock vs. Cx43 231, $p=0.908$, ns). The ability of tumor cells to prevent mural cell-mediated endothelial growth inhibition in co-culture was reversed when mural cells maintain expression of Cx43 (Cx43 231 Co vs.
231 Vector Co, $p=0.014$; Fig. 5b). Together, these data suggest that tumor-induced loss of heterocellular Cx43 gap junctions promotes endothelial proliferation by releasing endothelial cells from mural cell growth inhibition.

\section{Proliferation of tumor endothelium is increased and pericyte investiture decreased on a Cx43-reduced host background}

In order to address the in vivo significance of Cx43 loss on angiogenesis, Eo771 mouse mammary tumor cells were implanted into the mammary fat pad of female syngeneic $\mathrm{C} 57 \mathrm{Bl} / 6$ wild-type (WT) mice or mice that were bred to be heterozygous for $\mathrm{Cx} 43$ (Cx43 Het). Excised tumors from these mice were immunostained for the endothelial marker CD31. Representative images of this 


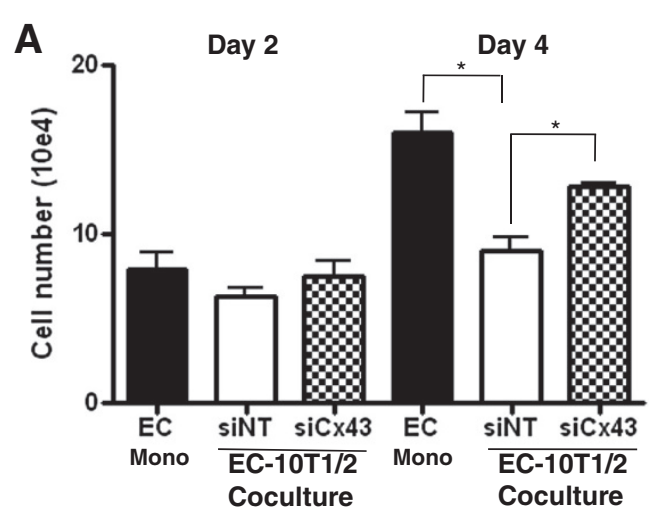

B

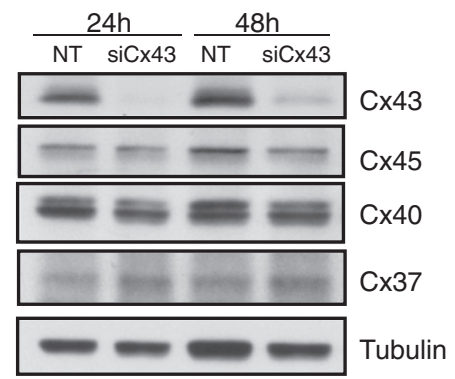

C

Day 2

Day 4

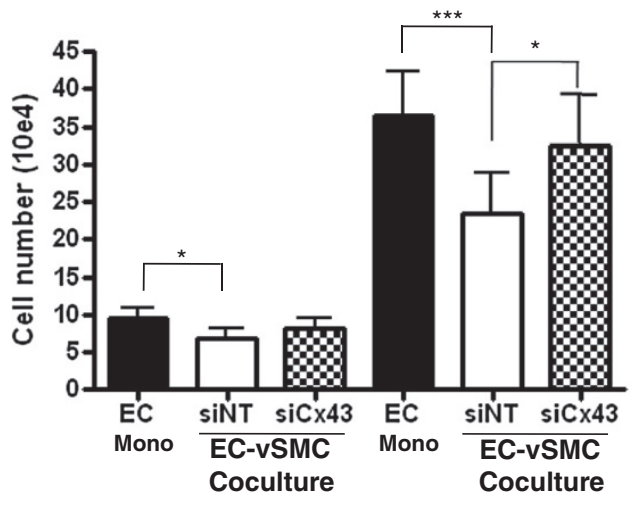

D
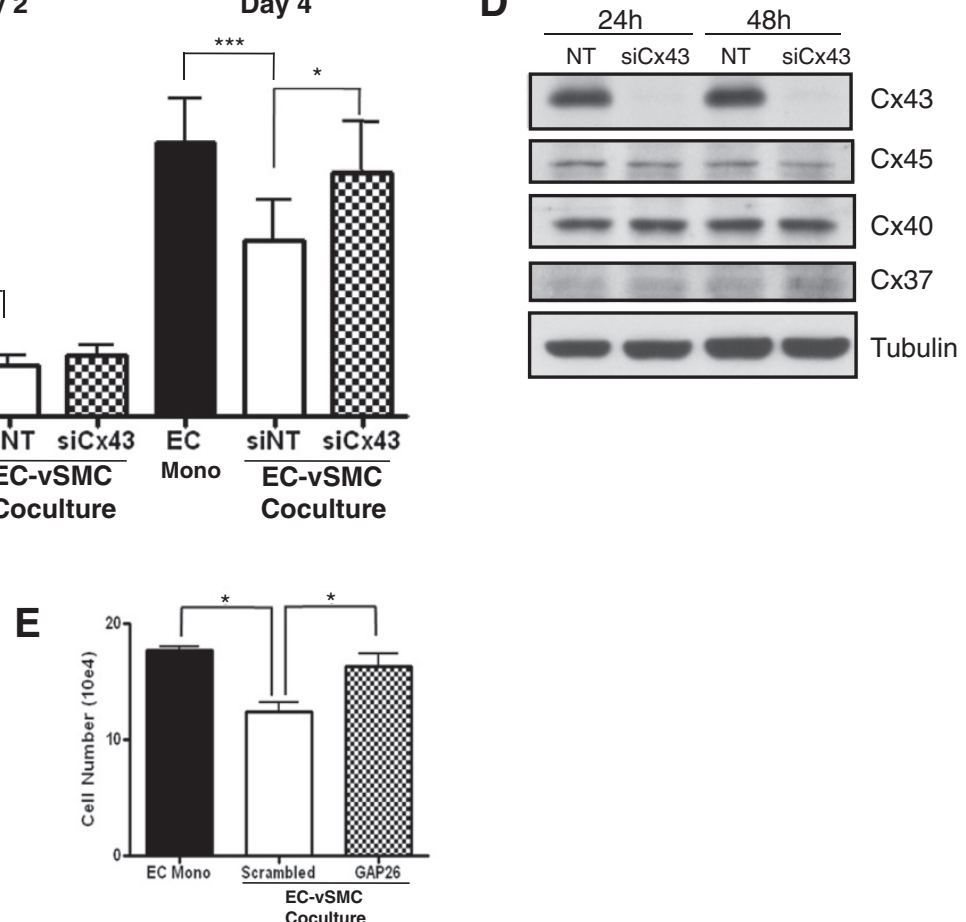

Fig. 4 Mural cell inhibition of endothelial cell proliferation requires mural cell CX43 and GJ communication. Labeled mural cells (a and b, C3H $10 \mathrm{~T} 1 / 2$ cells, or $\mathbf{c}$ and $\mathbf{d}$, vSMC) nucleofected with control non-targeting or (X43 siRNA were cultured with labeled HUVEC and effects on HUVEC proliferation assessed by cell counting followed by flow cytometry at indicated days. a. Pooled data from three independent experiments performed in triplicate using HUVEC from two different donors. $\left.{ }^{*} p<0.05\right)$. b. Western analysis of $C \times 43$ expression from representative experiment from A. c. Pooled data from five independent experiments performed in triplicate using VSMC from three different donors and HUVEC from two different donors $\left({ }^{*} p<0.05 ;{ }^{* * *} p=0.001\right)$. d. Western analysis of $C \times 43$ expression from representative experiment from C. e. Labeled mural cells were cultured with GFP-HUVEC for four days in the presence of GAP26 blocking peptide or control scrambled peptide and effects on HUVEC proliferation assessed as in A. Data shown are from a representative of two experiment performed in triplicate $\left(^{*} p<0.05\right)$

staining demonstrate increased CD31-positive (CD31+) endothelial cells in the tumors from Cx43 Het mice compared to those from WT mice (Fig. 6a, top panel). Quantification of the average area of CD31+ endothelial cells confirmed a significant $47.7 \%$ increase in area of CD31+ cells (Fig. 6b lower panel, $p=0.023$ ) in Cx43 Het mice compared to WT mice. The presence of NG2+ pericytes on these vessels (Fig. 6b, top panel) was significantly decreased over two-fold in the Cx43 Het mice compared to WT mice (Fig. 6b, lower panel, $\mathrm{p}<0.005$ ), suggesting decreased vessel stabilization. Despite the observed increase in vascularity, no change in the growth rate over time (Fig. 6c) or final tumor mass (Fig. 6d) was observed in tumors from Cx43 Het mice compared to WT.

\section{Discussion}

The ability of pericytes to prevent endothelial proliferation is well documented $[1,17,18]$, and the vasculature 


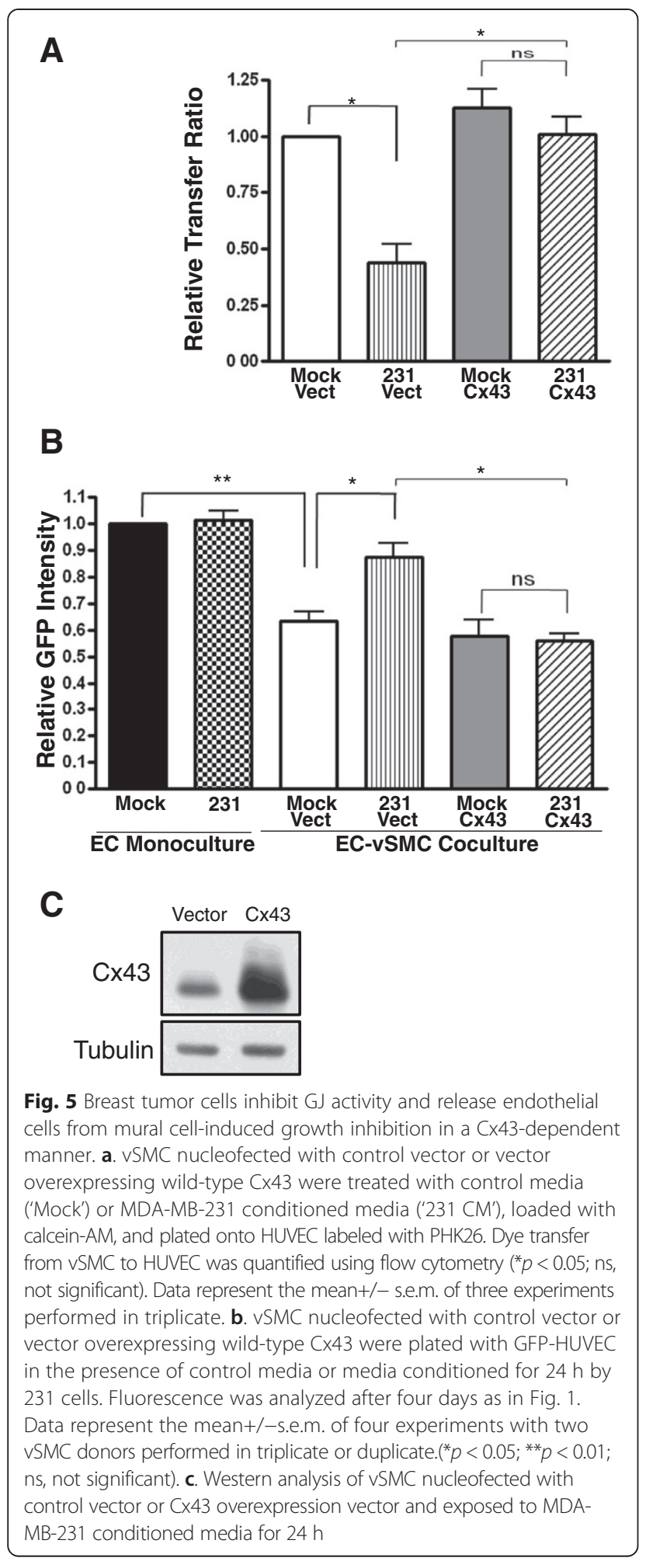

of angiogenic pathologies such as inflammatory arthritis [24], diabetic retinopathy [25], and cancer $[4,5]$ are characterized by decreased pericyte association with endothelium. The importance of the initial dissociation step in tumor angiogenesis is underscored by the ability of breast cancer cells to increase initiation of angiogenesis without increasing neovessel growth rate [26]. Here we have used an in vitro model system to examine the ability of tumors to free endothelial cells from mural cell-induced quiescence in order to mimic this initiation. Mechanistically, we have determined that aggressive tumors may target mural cell $\mathrm{Cx} 43$ to prevent or disrupt these functional inhibitory associations to allow for a proliferative and angiogenic endothelium. Our data further indicate a previously unappreciated requirement for mural cell Cx43 expression and gap junction activity in mediating the functional interactions required for maintenance of endothelium in a quiescent state. Since enforced mural cell coverage may decrease angiogenesis $[27,28]$ and enhance drug delivery [29], strategies to prevent mural Cx43 loss may prove therapeutically beneficial.

Although Cx43 was previously shown to be required for the contact-dependent endothelial cell-induced differentiation of mural cell precursors into functional mural cells [9], our data extend these findings to demonstrate that continued presence of these junctions in already differentiated mural cells is required for maintenance of endothelial quiescence. While several growth factor families including PDGF, Angiopoietin-1, sphingosine-1-phosphate, and TGF$\beta$ have been implicated in the recruitment of mural cells during the 'termination phase' of normal angiogenesis (reviewed in [30]), the mechanisms by which tumors preclude functional inhibitory interactions between mural cells and endothelial cells have remained ill-defined. Our data suggest that downregulation of mural cell $\mathrm{Cx} 43$ by tumors may represent a pivotal point in the initiation of angiogenesis, and/or the ability of tumors to impede the tight functional mural cell-endothelial cell interactions which would render a newly formed vessel mature and quiescent. While the ability to downregulate mural cell $\mathrm{Cx} 43$ is restricted to highly aggressive MDA-MB-231 and MDA-MB-468 cell lines in our study, we cannot preclude the possibility that other tumor cells may functionally inactivate Cx43 gap junctions by other means such as phosphorylation or altered $\mathrm{Cx} 43$ localization, which can be regulated by different mechanisms. Indeed, it has been demonstrated that breast tumor cells such as MCF7 can recruit mural cells away from vessels ex vivo [31], and inactivating phosphorylation of $\mathrm{Cx} 43$ on tumor capillaries has been reported [32]. These data are consistent with the possibility that tumor-induced loss of Cx43 gap junction function may diminish the ability of mural cells to associate appropriately with the underlying endothelium, even when they are physically present in the microenvironment.

A connection between Cx43/gap junction decrease and pericyte dissociation has been suggested in other angiogenic pathologies such as diabetic retinopathy, a condition characterized by loss of pericytes from retinal vessels. 


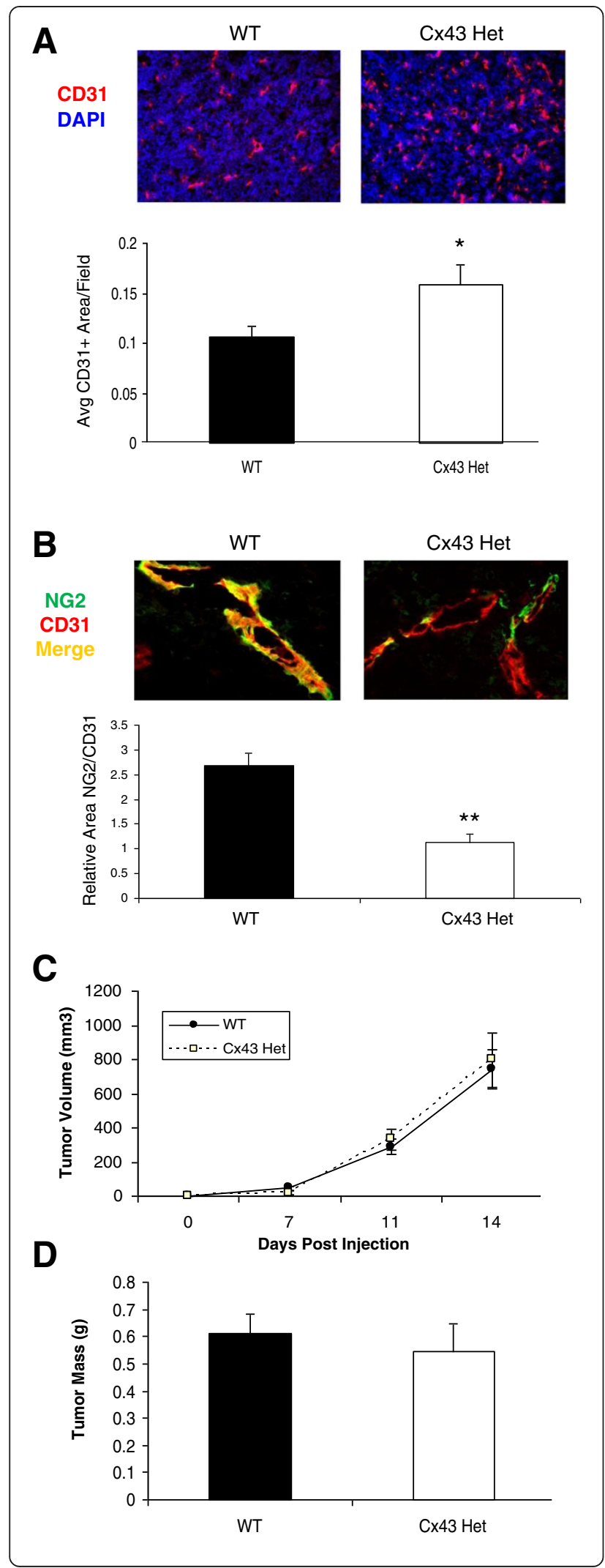

Fig. 6 Cx43 deficiency results in enhanced angiogenesis and decreased stabilization but does not affect tumor growth. Eo771 cells were implanted into the mammary fat pad of female mice that were wild-type ('WT') or heterozygous ('Cx43') for Cx43. a. Representative tumor sections stained for CD31 (red) shown at 20x. Bottom panel represents quantification of average CD31+ area per field $(n=8$ tumors/group). ${ }^{*} p<0.05$. b. Representative tumor sections stained for NG2 (green) and CD31 (red). Bottom panel represents quantification of relative area of NG2 positivity of CD31 positive vessels ( 5 fields/ tumor, $n=3$ tumors per group); ${ }^{*} p<0.01$. c. Tumors were measured using calipers and volume estimated using the formula $(((L+W) / 2) \wedge 3) / 2$. d. Tumor mass was determined at the time of sacrifice $(n=10-11)$

Previous studies demonstrated that high glucose levels downregulate Cx43 on mural cells [33] and downregulate $\mathrm{Cx} 43$ on endothelial cells [34] in vitro. Consistent with these findings, a decrease in GJ-mediated dye transfer between retinal pericytes and endothelial cells [35] and a decrease in Cx43 protein in retinal lysates [25] is observed in hyperglycemic rodent models of diabetes. Of note, global Cx43 heterozygous mice exhibit retinal pericyte loss similar to that observed in the diabetic model [25], although a mechanistic link between Cx43/GJIC and lack of proper pericyte association on tumor vasculature has not previously been reported. Similarly, conditions such as ischemia or hypoxia cause pericyte dissociation from brain microvessels in vivo [36, 37], and uncouples GIC in ex vivo retinal microvessels [38]. Furthermore, endothelialspecific loss of the TGF- $\beta$ signaling mediator Smad4 results in vascular defects including impaired association between endothelial cells and pericytes and loss of endothelial Cx43 [39]. Together with our findings, these data from pathologic and genetic models are consistent with a model in which Cx43 loss in one or both vascular cell compartments results in functional pericyte dissociation from endothelium as a consequence of loss of heterocellular GJ communication.

Previous studies have demonstrated that expression of mural $\mathrm{Cx} 43$ is required for the endothelial cellinduced differentiation of mural cell precursors into functional, mature mural cells [9]. Since we find that tumors downregulate mural cell $\mathrm{Cx} 43$, our data may therefore suggest an explanation for the decreased expression of mature differentiation markers in tumor vessel-associated pericytes [4]. An alternative explanation for decreased mural cell stabilization of tumor vessels is that decreased $\mathrm{Cx} 43$ in mural precursors may impair their ability to migrate, as $\mathrm{Cx} 43$ is required for the adhesion and motility of several cell types [40]. Additional studies will be required to confirm whether the tumor-induced loss of Cx43 in mural cells contributes to other aspects of vessel defects that are observed in tumors. Interestingly, it has recently been proposed 
that loss of GJ communication along the vascular wall could result in the arterio-venous shunting defect that is commonly found in tumor vasculature [41]. To our knowledge, our data provide the first empirical evidence that tumors can functionally disrupt vascular GJ activity in support of this hypothesis.

To confirm a requirement for $\mathrm{Cx} 43$ in maintaining vessel quiescence in vivo, we analyzed tumor angiogenesis in $\mathrm{Cx} 43$ heterozygous mice with reduced $\mathrm{Cx} 43$ levels. In this experiment, we observed an increase in vascularity as assessed by CD31+ endothelial cells in hosts with reduced Cx43 (Fig. 6a, b). Surprisingly, the observed increase in vascularity in the $\mathrm{Cx} 43$ Het mice was not associated with an overall increase in tumor size or growth rate of the Eo771 implanted tumors. It is unclear why tumor growth rate in this model is not increased despite increased vascularity, but possible reasons include that angiogenesis in a wild-type host is not rate-limiting for the highly aggressive Eo771 tumor, or that the excess vessels generated in Cx43-deficient animals may be inefficient or not wellperfused and therefore not provide a proliferative advantage for the tumor. Regardless of the explanation, the increased angiogenesis in Cx43-deficient animals is consistent with our in vitro observations that mural cells lacking sufficient $\mathrm{Cx} 43$ cannot exert growth inhibitory influence on endothelial cells. Because we used a global Cx43 heterozygote as host, however, we cannot preclude the possibility that $\mathrm{Cx} 43$ loss in endothelial cells or host cells other than mural cells may cause or allow increased endothelial proliferation. In contrast with this possibility, previous work suggests that $\mathrm{Cx} 43$ heterozygosity is associated with apoptosis of retinal endothelial cells [25], and knockdown of Cx43 in endothelial cells [42] or endothelial progenitor cells impairs proliferation [43]. To better define the role of mural cell $\mathrm{Cx} 43$ in tumor vessels, we generated smooth muscle-specific Cx43 knockout mice to use as a tumor host for syngeneic tumor cells. However, we found that a cross between SM-22 $\alpha$-KI mice [44] with Cx43-floxed mice [15] results in neonatal lethality of homozygotes (postnatal day $8-12$, unpublished observation). The phenotype of these mice is currently being characterized.

\section{Conclusions}

Our studies identify a novel role for mural cell Cx43 in maintaining quiescence and stability of the vasculature, and suggest that targeting of this molecule by tumors may play a role in the diminished functional mural cellendothelial association in tumors that allows tumor endothelium to become and remain proliferative. Mural cell Cx43 and vascular GJ communication may therefore prove to be attractive targets to prevent tumor angiogenesis and/or facilitate vessel normalization.

\section{Additional files}

Additional file 1: Figure S1. Conditioned media from MDA-MB-231 cells does not negatively impact SMC proliferation. VSMC plated in monoculture were subjected to MTS assay four days post-plating. ( $n=3$ experiments performed in triplicate; $p<0.05$ ).

Additional file 2: Figure S2. GAP26 Peptide does not inhibit endothelial proliferation. GFP-HUVEC monocultures were treated for four days in the presence of GAP26 blocking peptide or control scrambled peptide (Scr), then proliferation assessed by cell counting followed by flow cytometry. Data represent mean of three experiments performed in duplicate or triplicate.

\section{Abbreviations}

C: Celsius; Cx: Connexin; CM: Conditioned media; EC: Endothelial cells; ECL: Enhanced chemiluminesence; GFP: Green fluorescent protein; GJ: Gap junction; GJIC: Gap junction intercellular communication; HBMEC: Human brain microvascular endothelial cells; HBVP: Human brain vascular pericytes; Het: Heterozygous; HUVEC: Human umbilical vein endothelial cells; NG2: Neuron-glial chondroitin sulphate proteoglycan antigen 2; $\mathrm{NIH}$ : National Institutes of Health; OCT: Optimal cutting temperature compound; vSMC: Vascular smooth muscle cells; WT: Wild-type.

\section{Competing interests}

The authors declare that they have no competing interests.

\section{Authors' contributions}

MC performed co-cultures, parachute assays, Q-PCR, confocal and some immunoblot analysis and helped draft the manuscript. CN and WC performed and analyzed the animal studies and contributed some immunoblot analysis. KDB contributed to study design, participated in immunoblot analyses and assisted with drafting of the manuscript. LDC carried out statistical analysis. LJMB designed the studies, participated in its coordination and helped draft the manuscript. All authors read and approved the final manuscript.

\section{Acknowledgements}

This work was supported in part by Public Health Service grants CA115829 and CA138727 (LJMB) from the National Institutes of Health (NIH). The use of the WF CCC core facilities including Cancer Center Biostatistics Core, Flow Cytometry Facility, the Cellular Imaging Core, and the Cell and Virus Vector Core Laboratory was supported, in part, by WF CCC NIH grant CA012197. The content is solely the responsibility of the authors and does not necessarily represent the official views of the National Cancer Institute or the $\mathrm{NIH}$.

\section{Author details}

${ }^{1}$ Department of Radiation Oncology, Wake Forest School of Medicine, Medical Center Boulevard, Winston-Salem, NC 27157, USA. ²Department of Cancer Biology, Wake Forest School of Medicine, Medical Center Boulevard, Winston-Salem, NC 27157, USA. ${ }^{3}$ Department of Biostatistical Sciences, Wake Forest School of Medicine, Medical Center Boulevard, Winston-Salem, NC 27157, USA. ${ }^{4}$ Wake Forest Comprehensive Cancer Center, Wake Forest School of Medicine, Medical Center Boulevard, Winston-Salem, NC 27157, USA.

${ }^{5}$ Current address: Duke Eye Center, 2351 Erwin Road, AERI Room 4000, Durham, NC 27705, USA.

Received: 19 November 2014 Accepted: 6 May 2015 Published online: 23 May 2015

\section{References}

1. Orlidge A, D'Amore PA. Inhibition of capillary endothelial cell growth by pericytes and smooth muscle cells. J Cell Biol. 1987;105(3):1455-62.

2. Stratman AN, Malotte KM, Mahan RD, Davis MJ, Davis GE. Pericyte recruitment during vasculogenic tube assembly stimulates endothelial basement membrane matrix formation. Blood. 2009;114(24):5091-101.

3. Hayashi K, Nakao S, Nakaoke R, Nakagawa S, Kitagawa N, Niwa M. Effects of hypoxia on endothelial/pericytic co-culture model of the blood-brain barrier. Regul Pept. 2004;123(1-3):77-83.

4. Morikawa S, Baluk P, Kaidoh T, Haskell A, Jain RK, McDonald DM. Abnormalities in pericytes on blood vessels and endothelial sprouts in tumors. Am J Pathol. 2002;160(3):985-1000. 
5. Abramsson A, Berlin O, Papayan H, Paulin D, Shani M, Betsholtz C. Analysis of mural cell recruitment to tumor vessels. Circulation. 2002;105(1):112-7.

6. Maeda S, Tsukihara T. Structure of the gap junction channel and its implications for its biological functions. Cell Mol Life Sci. 2011;68(7):1115-29.

7. $\mathrm{Hu}$ J, Cotgreave IA. Differential regulation of gap junctions by proinflammatory mediators in vitro. J Clin Invest. 1997:99(10):2312-6.

8. Larson DM, Carson MP, Haudenschild CC. Junctional transfer of small molecules in cultured bovine brain microvascular endothelial cells and pericytes. Microvasc Res. 1987;34(2):184-99.

9. Hirschi KK, Burt JM, Hirschi KD, Dai C. Gap junction communication mediates transforming growth factor-beta activation and endothelial-induced mural cell differentiation. Circ Res. 2003;93(5):429-37.

10. Haefliger JA, Nicod P, Meda P. Contribution of connexins to the function of the vascular wall. Cardiovasc Res. 2004;62(2):345-56.

11. Li WE, Waldo K, Linask KL, Chen T, Wessels A, Parmacek MS, et al. An essential role for connexin43 gap junctions in mouse coronary artery development. Development. 2002;129(8):2031-42.

12. Walker DL, Vacha SJ, Kirby ML, Lo CW. Connexin43 deficiency causes dysregulation of coronary vasculogenesis. Dev Biol. 2005;284(2):479-98.

13. Tomasetto C, Neveu MJ, Daley J, Horan PK, Sager R. Specificity of gap junction communication among human mammary cells and connexin transfectants in culture. J Cell Biol. 1993;122(1):157-67.

14. Livak KJ, Schmittgen TD. Analysis of relative gene expression data using real-time quantitative PCR and the 2(-Delta Delta C(T)) Method. Methods. 2001;25(4):402-8.

15. Liao Y, Day KH, Damon DN, Duling BR. Endothelial cell-specific knockout of connexin 43 causes hypotension and bradycardia in mice. Proc Natl Acad Sci U S A. 2001:98(17):9989-94.

16. Tomayko MM, Reynolds CP. Determination of subcutaneous tumor size in athymic (nude) mice. Cancer Chemother Pharmacol. 1989;24(3):148-54

17. Hirschi KK, Rohovsky SA, Beck LH, Smith SR, D'Amore PA. Endothelial cells modulate the proliferation of mural cell precursors via platelet-derived growth factor-BB and heterotypic cell contact. Circ Res. 1999;84(3):298-305

18. Crocker DJ, Murad TM, Geer JC. Role of the pericyte in wound healing. An ultrastructural study. Exp Mol Pathol. 1970;13(1):51-65.

19. Isakson BE, Duling BR. Heterocellular contact at the myoendothelial junction influences gap junction organization. Circ Res. 2005;97(1):44-51.

20. Isakson BE, Best AK, Duling BR. Incidence of protein on actin bridges between endothelium and smooth muscle in arterioles demonstrates heterogeneous connexin expression and phosphorylation. Am J Physiol Heart Circ Physiol. 2008;294(6):H2898-904.

21. Little T, Xia J, Duling BR. Dye tracers define differential endothelial and smooth muscle coupling patterns within the arteriolar wall. Circ Res. 1995;76:498-504.

22. Jiang JX, Gu S. Gap junction- and hemichannel-independent actions of connexins. Biochim Biophys Acta. 2005;1711(2):208-14.

23. Evans WH, Boitano S. Connexin mimetic peptides: specific inhibitors of gap-junctional intercellular communication. Biochem Soc Trans. 2001:29(Pt 4):606-12.

24. Kennedy A, Ng CT, Biniecka M, Saber T, Taylor C, O'Sullivan J, et al. Angiogenesis and blood vessel stability in inflammatory arthritis. Arthritis Rheum. 2010;62(3):711-21.

25. Bobbie MW, Roy S, Trudeau K, Munger SJ, Simon AM. Reduced connexin 43 expression and its effect on the development of vascular lesions in retinas of diabetic mice. Invest Ophthalmol Vis Sci. 2010;51(7):3758-63.

26. Watson JC, Redmann JG, Meyers MO, Alperin-Lea RC, Gebhardt BM, Delcarpio JB, et al. Breast cancer increases initiation of angiogenesis without accelerating neovessel growth rate. Surgery. 1997;122(2):508-13. discussion 513-504.

27. Bhattacharya A, Seshadri M, Oven SD, Toth K, Vaughan MM, Rustum YM Tumor vascular maturation and improved drug delivery induced by methylselenocysteine leads to therapeutic synergy with anticancer drugs. Clin Cancer Res. 2008;14(12):3926-32.

28. Tian S, Hayes AJ, Metheny-Barlow LJ, Li LY. Stabilization of breast cancer xenograft tumour neovasculature by angiopoietin-1. Br J Cancer. 2002:86(4):645-51.

29. Fukumura D, Jain RK. Tumor microvasculature and microenvironment: targets for anti-angiogenesis and normalization. Microvasc Res. 2007;74(2-3):72-84

30. Jain RK. Molecular regulation of vessel maturation. Nat Med. 2003;9(6):685-93.

31. Ronnov-Jessen L, Petersen OW, Koteliansky VE, Bissell MJ. The origin of the myofibroblasts in breast cancer. Recapitulation of tumor environment in culture unravels diversity and implicates converted fibroblasts and recruited smooth muscle cells. J Clin Invest. 1995:95(2):859-73.

32. Gould VE, Mosquera JM, Leykauf K, Gattuso P, Durst M, Alonso A. The phosphorylated form of connexin43 is up-regulated in breast hyperplasias and carcinomas and in their neoformed capillaries. Hum Pathol. 2005;36(5):536-45.

33. Li AF, Sato T, Haimovici R, Okamoto T, Roy S. High glucose alters connexin 43 expression and gap junction intercellular communication activity in retinal pericytes. Invest Ophthalmol Vis Sci. 2003;44(12):5376-82.

34. Sato T, Haimovici R, Kao R, Li AF, Roy S. Downregulation of connexin 43 expression by high glucose reduces gap junction activity in microvascular endothelial cells. Diabetes. 2002;51(5):1565-71.

35. Oku H, Kodama T, Sakagami K, Puro DG. Diabetes-induced disruption of gap junction pathways within the retinal microvasculature. Invest Ophthalmol Vis Sci. 2001;42(8):1915-20.

36. Gonul E, Duz B, Kahraman S, Kayali H, Kubar A, Timurkaynak E. Early pericyte response to brain hypoxia in cats: an ultrastructural study. Microvasc Res. 2002;64(1):116-9.

37. Duz B, Oztas E, Erginay T, Erdogan E, Gonul E. The effect of moderate hypothermia in acute ischemic stroke on pericyte migration: an ultrastructural study. Cryobiology. 2007;55(3):279-84.

38. Yamanishi S, Katsumura K, Kobayashi T, Puro DG. Extracellular lactate as a dynamic vasoactive signal in the rat retinal microvasculature. Am J Physiol Heart Circ Physiol. 2006;290(3):H925-34.

39. Lan Y, Liu B, Yao H, Li F, Weng T, Yang G, et al. Essential role of endothelial Smad4 in vascular remodeling and integrity. Mol Cell Biol. 2007:27(21):7683-92.

40. Matsuuchi L, Naus CC. Gap junction proteins on the move: connexins, the cytoskeleton and migration. Biochim Biophys Acta. 2013;1828(1):94-108.

41. Pries AR, Hopfner M, le Noble F, Dewhirst MW, Secomb TW. The shunt problem: control of functional shunting in normal and tumour vasculature. Nat Rev Cancer. 2010;10(8):587-93.

42. Wang HH, Kung $\mathrm{Cl}$, Tseng $\mathrm{YY}$, Lin YC, Chen $\mathrm{CH}$, Tsai CH, et al. Activation of endothelial cells to pathological status by down-regulation of connexin43. Cardiovasc Res. 2008;79(3):509-18.

43. Wang HH, Su CH, Wu YJ, Li JY, Tseng YM, Lin YC, et al. Reduction of connexin43 in human endothelial progenitor cells impairs the angiogenic potential. Angiogenesis. 2013;16(3):553-60.

44. Zhang J, Zhong W, Cui T, Yang M, Hu X, Xu K, et al. Generation of an adult smooth muscle cell-targeted Cre recombinase mouse model. Arterioscler Thromb Vasc Biol. 2006:26(3):e23-4.

\section{Submit your next manuscript to BioMed Central and take full advantage of:}

- Convenient online submission

- Thorough peer review

- No space constraints or color figure charges

- Immediate publication on acceptance

- Inclusion in PubMed, CAS, Scopus and Google Scholar

- Research which is freely available for redistribution

Submit your manuscript at www.biomedcentral.com/submit 